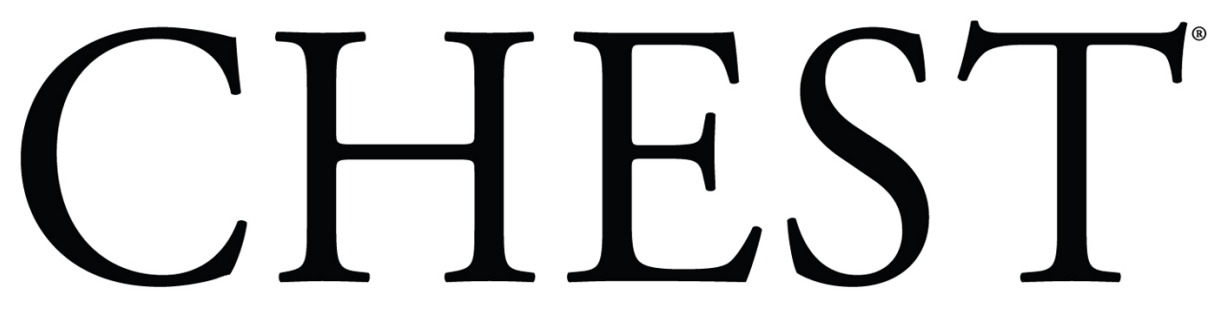

Official publication of the American C ollege of Chest Physicians

\title{
Effects of a Walking Aid in COPD Patients Receiving Oxygen Therapy
}

Ernesto Crisafulli, Stefania Costi, Francesco De Blasio, Gianluca Biscione, Francesca Americi, Sergio Penza, Erika Eutropio, Franco

Pasqua, Leonardo M. Fabbri and Enrico M. Clini

Chest 2007;131;1068-1074

DOI 10.1378/chest.06-2108

The online version of this article, along with updated information and services can be found online on the World Wide Web at: http://chestjournals.org/cgi/content/abstract/131/4/1068

CHEST is the official journal of the American College of Chest

Physicians. It has been published monthly since 1935. Copyright 2007 by the American College of Chest Physicians, 3300 Dundee Road, Northbrook IL 60062. All rights reserved. No part of this article or PDF may be reproduced or distributed without the prior written permission of the copyright holder

(http://www.chestjournal.org/misc/reprints.shtml). ISSN: 0012-3692.

A M E R I C A N C O L L E G E O F

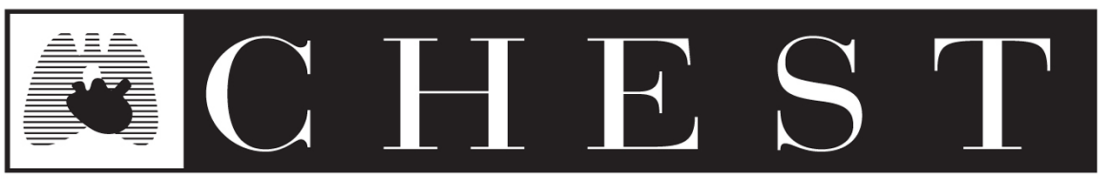
$\begin{array}{llllllllll}\mathrm{P} & \mathrm{H} & \mathrm{Y} & \mathrm{S} & \mathrm{I} & \mathrm{C} & \mathrm{I} & \mathrm{A} & \mathrm{N} & \mathrm{S}\end{array}$ 


\title{
Effects of a Walking Aid in COPD Patients Receiving Oxygen Therapy*
}

\author{
Ernesto Crisafulli, MD; Stefania Costi, RT; Francesco De Blasio, MD, FCCP; \\ Gianluca Biscione, MD, FCCP; Francesca Americi, RT; Sergio Penza, RT; \\ Erika Eutropio, RT; Franco Pasqua, MD, FCCP; \\ Leonardo M. Fabbri, MD, FCCP; and Enrico M. Clini, MD, FCCP
}

Study objectives: To elucidate whether a simple walking aid may improve physical performance in COPD patients with chronic respiratory insufficiency who usually carry their own heavy oxygen canister.

Design: Randomized crossover trial.

Setting: Physiopathology laboratory of three rehabilitation centers.

Patients and interventions: We studied 60 stable COPD patients (mean age, $70.6 \pm 7.9$ years; $\mathrm{FEV}_{1}, 44.8 \pm 14.3 \%$ of predicted $[ \pm \mathrm{SD}]$ ) with chronic respiratory insufficiency who randomly performed, on 2 consecutive days, a standardized 6-min walking test using two different modalities: a full-weight oxygen canister transported using a small wheeled cart and pulled by the patient (Aid modality) or full-weight oxygen canister carried on the patient's shoulder (No-Aid modality).

Measurements and results: The distance walked, peak effort dyspnea, and leg fatigue scores as primary outcomes, and other cardiorespiratory parameters as secondary outcomes were recorded during both tests. A significant difference $(p<0.05)$ between the two tests occurred for all the measured outcomes in favor of the Aid modality. Most importantly, significant changes for distance $(+43 \mathrm{~m}, \mathrm{p}<0.001)$, peak effort dyspnea $(-2.0$ points, $\mathrm{p}<0.001)$, leg fatigue $(-1.4$ points, $\mathrm{p}<0.001$ ), as well as for mean and nadir oxygen saturation and heart rate with the Aid modality (but not with the No-Aid modality) were recorded in the subgroup of patients walking $<300 \mathrm{~m}$ at baseline.

Conclusions: This study suggests that a simple walking aid may be helpful in COPD patients receiving long-term oxygen therapy, particularly in those with lower residual exercise capacity.

(CHEST 2007; 131:1068-1074)

Key words: exercise; 6-min walking test; symptoms; wheeled cart

Abbreviations: $\mathrm{FIO}_{2}=$ fraction of inspired oxygen; $\mathrm{HR}=$ heart rate; $6 \mathrm{MWT}=6$-min walking test; LTOT $=$ long-term oxygen therapy; $\mathrm{SaO}_{2}=$ arterial oxygen saturation

$\mathbf{P}$ atients with COPD have reduction in functional exercise capacity as the disease progresses. In these patients, dyspnea may become so disabling that

${ }^{*}$ From Departments of Pulmonary Rehabilitation (Drs. Crisafulli and Clini, and Ms. Eutropio) and Oncology, Haematology, and Pneumology (Dr. Fabbri and Ms. Costi), University of Modena; Clinic Center Private Hospital (Dr. De Blasio and Mr. Penza), Pulmonary Rehabilitation Unit, Napoli; and Department of Pulmonary Rehabilitation (Drs. Biscione, Pasqua, and Ms. Americi), IRCCS San Raffaele, Velletri, Rome, Italy.

The authors have reported to the ACCP that no significant conflicts of interest exist with any companies/organizations whose products or services may be discussed in this article. they lead a sedentary lifestyle, which results in further deconditioning, worsening of symptoms, and reduced quality of life. ${ }^{1}$

Manuscript received August 23, 2006; revision accepted December 6, 2006 .

Reproduction of this article is prohibited without written permission from the American College of Chest Physicians (www.chestjournal. org/misc/reprints.shtml).

Correspondence to: Enrico M. Clini, MD, FCCP, University of Modena-Reggio Emilia, Department of Pulmonary Rehabilitation, Ospedale Villa Pineta, Italy, Via Gaiato 127, 41026 Pavullo n/F (MO); e-mail: clini.enrico@unimore.it

DOI: 10.1378/chest.06-2108 
It is noteworthy that walking represents a fundamental ability to perform several activities of daily living. Furthermore, pulmonary rehabilitation programs aim to encourage walking as an important, useful, and preferred form of exercise for many patients with COPD. ${ }^{2}$

Wheeled walking aids are sometimes prescribed for patients with COPD to improve their functional exercise capacity. ${ }^{3}$ Until now, information on the influence of wheeled walking aids in patients with COPD was limited because of studies that have used small sample sizes ${ }^{3-5}$ or subjects with mild disease. ${ }^{5}$ More recently, it has been shown that walking with a rollator (which supports the upper arms) is effective in improving both physical performance and reducing dyspnea in severely disabled patients with COPD. ${ }^{6}$

In patients with chronic respiratory insufficiency and preserved walking ability but needing external oxygen, the use of a heavy portable oxygen canister (stroller) can produce an immediate limitation of functional exercise capacity due to its weight and the increasing respiratory and skeletal muscle load. Inherent to this, no study has yet investigated which clinical effects are determined when pulling the oxygen canister on a wheeled cart during deambulation. This study, therefore, was undertaken to compare walking distance, symptoms, and main physiologic parameters during walking with the oxygen canister carried on the shoulder, or pulled using a small, wheeled cart in COPD patients receiving long-term oxygen therapy (LTOT).

\section{Materials AND Methods}

\section{Patients}

Consecutive COPD inpatients who were admitted to a comprehensive pulmonary rehabilitation program from January to December 2005 at the hospital facilities of Villa Pineta (GaiatoMO), IRCCS San Raffaele (Velletri-Roma), and Clinic Center (Napoli) were recruited. The predetermined recruitment of 20 patients per center was finalized.

Eligible patients had to receive LTOT for at least 6 months before enrollment and be in stable condition with no evidence of acute exacerbation or change in medication in the previous 4 weeks. The diagnosis of COPD was been made according to the Global Initiative for Chronic Obstructive Lung Disease stage and definition. ${ }^{7}$

All patients were all able to walk without assistance and perform the 6-min walking test (6MWT) according to the current recommendations. ${ }^{8}$ The presence of associated medical conditions that substantially limited exercise tolerance and performance (ie, symptomatic cardiovascular conditions, advanced osteoarthrosis) or malignancies represented study exclusion criteria.

The selected patients gave their consent to participate in the study. All trial procedures were conducted according to the Declaration of Helsinki.
Study Design

A randomized crossover design was used in this trial. Each patient performed two 6MWTs at the same time on 2 consecutive days in the first week after hospital admission. The test order was randomized according to a random-number table on the first day and then reversed on the second day. In each center, a small group of three or four trained physiotherapists unaware of the study purpose directed the tests on both days; both tests in the same patient were administered by the same physiotherapist.

The study condition consisted of testing the patient while he pulled a full oxygen canister on the floor using a small, light, wheeled cart (Aid modality). The control test was conducted by carrying the same oxygen canister on the patient's shoulder (No-Aid modality) [Fig 1]. A similar canister (3.5 kg) was used in both conditions; a continuous oxygen flow $(3 \mathrm{~L} / \mathrm{min})$ was similarly provided to patients during both tests.

\section{Pretest Evaluations}

Baseline data included primary demographic and anthropometric variables. Arterial blood was obtained from the radial artery at rest to obtain $\mathrm{PaO}_{2}, \mathrm{PaCO}_{2}$, and $\mathrm{pH}$ values by means of an automated analyzer (Model 850; Chiron Diagnostics; Medfield, MA). Patients breathed spontaneously with transnasal oxygen at the usual flow able to correct baseline hypoxemia; the fraction of inspired oxygen $\left(\mathrm{FIO}_{2}\right)$ was then calculated.

Forced lung volumes $\left(\mathrm{FEV}_{1}, \mathrm{FVC}\right)$ were assessed by means of a spirometer (Masterscope; Jaeger; Hoechberg, Germany). Predicted values according to Quanjer et $\mathrm{al}^{9}$ were used.

\section{$6 M W T$}

Standardized instructions for 6MWT and encouragement were provided to patients according to recommended guidelines. ${ }^{8}$ The $6 \mathrm{MWT}$ is a measure widely used in clinical practice to determine exercise tolerance in COPD patients. In the present study, both tests were conducted indoors in a corridor $(40 \mathrm{~m}$ in length, and $3 \mathrm{~m}$ in width) similar in both centers, under quiet conditions with a minimum of distractive stimuli. All subjects performed at least one practice walk before data collection in order to minimize learning and practice effects. ${ }^{10}$ Cardiorespiratory functions were continuously monitored at rest and during the test by means of a finger probe pulse oximeter (Pulsox 3; Minolta; Tokyo, Japan).
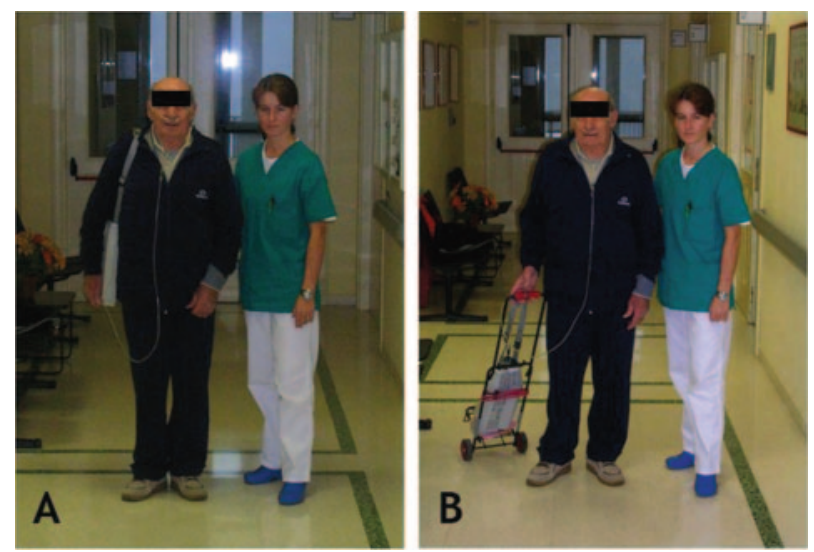

Figure 1. Experimental setting of the two 6MWTs. Left, A: the oxygen canister is carried on the patient's shoulder. Right, B: the oxygen canister is transported using a small, light, wheeled cart. 
The patient's perceived peak effort dyspnea and leg fatigue were measured by pointing to a number or phrase on a 10-point modified Borg scale ${ }^{11}$ set in large type on a sheet. This assessment was made during the last minute of walking. Furthermore, the walking speed (kilometers per hour) was calculated by recording the distance walked in each minute.

\section{Outcomes}

Primary: Exercise tolerance (as assessed by means of the timed walking distance during 6MWT), peak effort dyspnea, and leg fatigue were the primary outcomes of the study.

Secondary: Mean arterial oxygen saturation $\left(\mathrm{SaO}_{2}\right)$ and heart rate $(\mathrm{HR})$ values at rest and during the walking period, $\mathrm{SaO}_{2}$ mean change, and $\mathrm{SaO}_{2}$ nadir represented the secondary study outcomes.

\section{Statistical Analysis}

Analysis of study variables was performed using a statistical software package (SPSS, version 8.0; SPSS; Chicago, IL). All study data were analyzed in the total sample and in two subgroups of patients according to their ability to walk $(<300 \mathrm{~m}$ or $>300 \mathrm{~m}$ on baseline standard 6MWT), as previously suggested. $3,6,12$

Results are expressed as mean with SD for descriptive data or mean with SE for all other measures. Differences of the outcome measures in the No-Aid and Aid modalities were analyzed using a two-tailed Student $t$ test. The Wilcoxon test for nonparametric variables was used to assess the difference in peak effort dyspnea and leg fatigue. For all statistical analyses, an $\alpha$ error $<5 \%$ was considered significant.

\section{Results}

\section{Sample Characteristics}

Sixty COPD patients (mean age, 70.6 years) were included in the study. General characteristics of the study sample are shown in Table 1.
On average, patients had normal body mass index values and normal resting arterial oxygenation under correction with appropriate external $\mathrm{FIO}_{2}$. Thirtyseven patients walked $<300 \mathrm{~m}$ during standard 6MWT (No-Aid modality).

\section{MWT Distance}

Table 2 shows the results of the two walking session modalities in the total sample. Overall, distance walked and symptoms (primary outcomes) significantly improved when the patients pulled the oxygen canister using the wheeled cart (Aid modality). Moreover, cardiorespiratory parameters recorded during the walking activity (secondary outcomes) were significantly better with the Aid modality (Table 2), indicating this to be a less stressful condition. In particular, a less pronounced change of any $\mathrm{SaO}_{2}$ parameters was recorded during the Aid modality.

The same improvements in both primary and secondary outcomes due to the Aid modality were even more striking in the subgroup of patients who had a walking distance $<300 \mathrm{~m}$, whereas no significant differences were observed in the subgroup of patients who walked $>300 \mathrm{~m}$ (Table 3). 6MWT walking speed (kilometers per hour) for the Aid and No-Aid modalities is shown in Figure 2. In both modalities, there was a progressive decline in walking speed during the test. However, walking speed significantly and consistently improved with the Aid modality in the total sample and in the subgroup of less performing patients in particular (Fig 2).

Table 1-General Characteristics of the Study Sample*

\begin{tabular}{|c|c|c|c|}
\hline Characteristics & $\begin{array}{l}\text { Total Sample } \\
\quad(\mathrm{n}=60)\end{array}$ & $\begin{array}{l}\text { Patients Who Walked } \leq 300 \mathrm{~m} \\
\qquad(\mathrm{n}=37)\end{array}$ & $\begin{array}{l}\text { Patients Who Walked }>300 \mathrm{~m} \\
\qquad(\mathrm{n}=23)\end{array}$ \\
\hline \multicolumn{4}{|l|}{ Sex } \\
\hline Male & 36 & 22 & 14 \\
\hline Female & 24 & 15 & 9 \\
\hline Age, yr & $70(8)$ & $69(8)$ & $72(7)$ \\
\hline Weight, kg & $74(17)$ & $76(18)$ & $71(16)$ \\
\hline Height, cm & $164(2)$ & $165(1)$ & $162(1)$ \\
\hline Body mass index, $\mathrm{kg} / \mathrm{m}^{2}$ & $27.7(7.0)$ & $28.3(7.8)$ & $26.8(5.6)$ \\
\hline $\begin{array}{l}\text { Supplemental oxygen required }\left(\mathrm{FIO}_{2}\right), \% \\
\text { FVC }\end{array}$ & \multicolumn{2}{|c|}{ FVC } & $25.1(2.5)$ \\
\hline $\mathrm{L}$ & $2.1(0.6)$ & $2.1(0.7)$ & $1.9(0.5)$ \\
\hline$\%$ predicted & $65.5(15.2)$ & $63.6(15.0)$ & $68.5(15.2)$ \\
\hline \multicolumn{4}{|l|}{$\mathrm{FEV}_{1}$} \\
\hline $\mathrm{L}$ & $0.9(0.3)$ & $1.0(0.3)$ & $0.9(0.3)$ \\
\hline$\%$ predicted & $44.8(14.3)$ & $46.3(15.7)$ & $42.3(11.7)$ \\
\hline $\mathrm{FEV}_{1} / \mathrm{FCV}, \%$ & $49.4(14.7)$ & $51.2(16.9)$ & $46.5(10.1)$ \\
\hline $\mathrm{PaO}_{2}, \mathrm{~mm} \mathrm{Hg}$ & $66.4(8.9)$ & $66.3(8.2)$ & $66.6(10.3)$ \\
\hline $\mathrm{PaCO}_{2}, \mathrm{~mm} \mathrm{Hg}$ & 48.1 (10.8) & $46.3(9.8)$ & $50.8(12.0)$ \\
\hline $\mathrm{PaO}_{2} / \mathrm{FIO}_{2}$ & $262(43)$ & $261(44)$ & $266(39)$ \\
\hline $\mathrm{pH}$ & $7.41(0.05)$ & $7.40(0.05)$ & $7.41(0.03)$ \\
\hline
\end{tabular}

*Data are presented as No. or mean (SD). 
Table 2-Outcomes During 6MWT Modalities in All Studied Patients*

\begin{tabular}{|c|c|c|c|}
\hline Outcomes & No-Aid & Aid & $\mathrm{p}$ Value \\
\hline Distance walked, m & $262(9)$ & $291(8)$ & 0.001 \\
\hline Distance walked, \% predicted & $60(2)$ & $67(2)$ & 0.001 \\
\hline Peak effort dyspnea, Borg score $†$ & $5.8(0.3)$ & $3.9(0.3)$ & 0.001 \\
\hline Peak effort leg fatigue, Borg score ${ }^{\dagger}$ & $5.1(0.2)$ & $3.6(0.2)$ & 0.001 \\
\hline $\mathrm{HR}$ at rest, beats/min & $99(2)$ & $98(1)$ & 0.672 \\
\hline Maximum HR during 6MWT, beats/min & $114(2)$ & $109(2)$ & 0.003 \\
\hline Maximum HR, \% predicted & $76(1)$ & $73(1)$ & 0.003 \\
\hline Peak effort respiratory rate, breaths/min & $28(1)$ & $25(1)$ & 0.001 \\
\hline $\mathrm{SaO}_{2}$ at rest, $\%$ & $95.0(0.3)$ & $95.4(0.2)$ & 0.084 \\
\hline $\mathrm{SaO}_{2}$ during $6 \mathrm{MWT}, \%$ & $90.1(0.3)$ & $91.2(0.3)$ & 0.001 \\
\hline Arterial oxyhemoglobin desaturation during 6MWT, \% & $4.9(0.3)$ & $4.2(0.3)$ & 0.027 \\
\hline Nadir of arterial oxyhemoglobin desaturation during $6 \mathrm{MWT}, \%$ & $86.6(0.6)$ & $87.3(0.6)$ & 0.086 \\
\hline
\end{tabular}

*Data are presented as mean (SE).

$\nmid$ Differences calculated using Wilcoxon test.

\section{DisCUSSION}

This study shows that walking with a wheeled cart is able to improve distance, symptoms, and cardiopulmonary parameters in COPD patients receiving LTOT. These results are of particular relevance among the subgroup of patients who are more disabled.

Although there are still not sufficient data in the literature regarding activities in patients receiving LTOT, a randomized controlled trial ${ }^{13}$ has shown that outdoor walking distance improves in patients receiving portable oxygen with respect to those receiving oxygen concentrators only. Nevertheless, only $60 \%$ of patients provided with a portable oxygen device use it outdoors and for walking. ${ }^{13}$

One of the possible explanations for this finding could be the weight of the device bearing on the patient's shoulder during outdoor use. Additionally, the load of a portable device might also negatively influence the patient's walking speed, which in turn may have practical consequences in everyday life. Indeed, walking speed frequently represents a practical issue in elderly pedestrians who are at risk of being struck by cars when crossing the street ${ }^{14}$; in that study, patients walking below the threshold limit of $300 \mathrm{~m}$ in $6 \mathrm{MWT}$ are those performing at a speed that exposes them to the above-mentioned risk; therefore, this subgroup of disabled patients should be of particular interest when strategies for any functional and/or practical improvements are considered (as in the present study).

Previous trials have already shown that the use of a rollator as a wheeled walking aid during standard $6 \mathrm{MWT}$ is associated with a significant improvement in physical performance, dyspnea, ${ }^{6,15,16}$ and oxygenation $^{17,18}$ in patients with COPD. Taking into consideration these data, we then hypothesized that COPD patients with chronic respiratory insuffi-

Table 3-Outcomes During 6MWT Modalities in Patients With Different Levels of Walking Ability*

\begin{tabular}{|c|c|c|c|c|c|c|}
\hline \multirow[b]{2}{*}{ Outcomes } & \multicolumn{3}{|c|}{ Patients Who Walked $\leq 300 \mathrm{~m}$} & \multicolumn{3}{|c|}{ Patients Who Walked > $>300 \mathrm{~m}$} \\
\hline & No-Aid & Aid & $\mathrm{p}$ Value & Aid & No-Aid & $\mathrm{p}$ Value \\
\hline Distance, $\mathrm{m}$ & $213(7)$ & $256(8)$ & 0.001 & $340(6)$ & $349(7)$ & 0.147 \\
\hline Distance, $\%$ predicted & $48(2)$ & $59(3)$ & 0.001 & $79(4)$ & $80(3)$ & 0.251 \\
\hline Peak effort dyspnea, Borg score $\nmid$ & $6.0(0.3)$ & $4.0(0.3)$ & 0.001 & $5.5(0.4)$ & $3.8(0.5)$ & 0.001 \\
\hline Peak leg effort fatigue, Borg score ${ }^{\dagger}$ & $5.1(0.3)$ & $3.7(0.3)$ & 0.001 & $5.1(0.4)$ & $3.4(0.3)$ & 0.001 \\
\hline $\mathrm{HR}$ at rest, beats/min & $101(3)$ & $99(2)$ & 0.522 & $95(3)$ & $96(2)$ & 0.755 \\
\hline Maximum HR during 6MWT, beats/min & $116(2)$ & $111(2)$ & 0.013 & $111(4)$ & $107(3)$ & 0.107 \\
\hline Maximum HR, \% predicted & $77(1)$ & $74(1)$ & 0.017 & $75(3)$ & $73(2)$ & 0.093 \\
\hline Peak effort respiratory rate, breaths/min & $29(1)$ & $26(1)$ & 0.001 & $26(1)$ & $23(1)$ & 0.007 \\
\hline $\mathrm{SaO}_{2}$ at rest, $\%$ & $95.3(0.5)$ & $95.5(0.3)$ & 0.127 & $94.9(0.4)$ & $95.4(0.3)$ & 0.352 \\
\hline $\mathrm{SaO}_{2}$ during $6 \mathrm{MWT}, \%$ & $89.8(0.4)$ & $91.3(0.4)$ & 0.001 & $90.6(0.5)$ & $91.0(0.5)$ & 0.307 \\
\hline Arterial oxyhemoglobin saturation during 6MWT, \% & $5.2(0.4)$ & $4.1(0.4)$ & 0.001 & $4.4(0.5)$ & $4.3(0.5)$ & 0.965 \\
\hline $\begin{array}{l}\text { Nadir of arterial oxyhemoglobin saturation during } \\
\text { 6MWT, \% }\end{array}$ & $86.1(0.9)$ & $87.2(0.9)$ & 0.030 & $87.5(0.8)$ & $87.4(0.8)$ & 0.940 \\
\hline
\end{tabular}

*Data are presented as mean (SE).

$\nmid$ Differences calculated using a Wilcoxon test. 


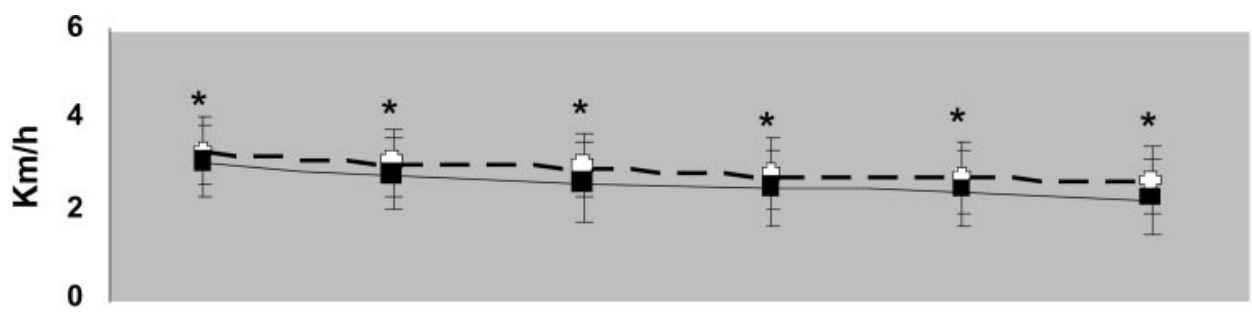

A

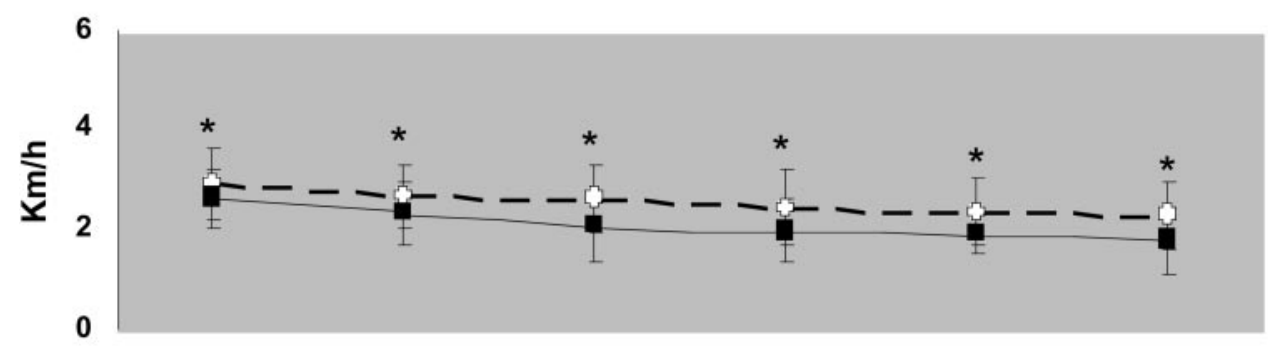

B

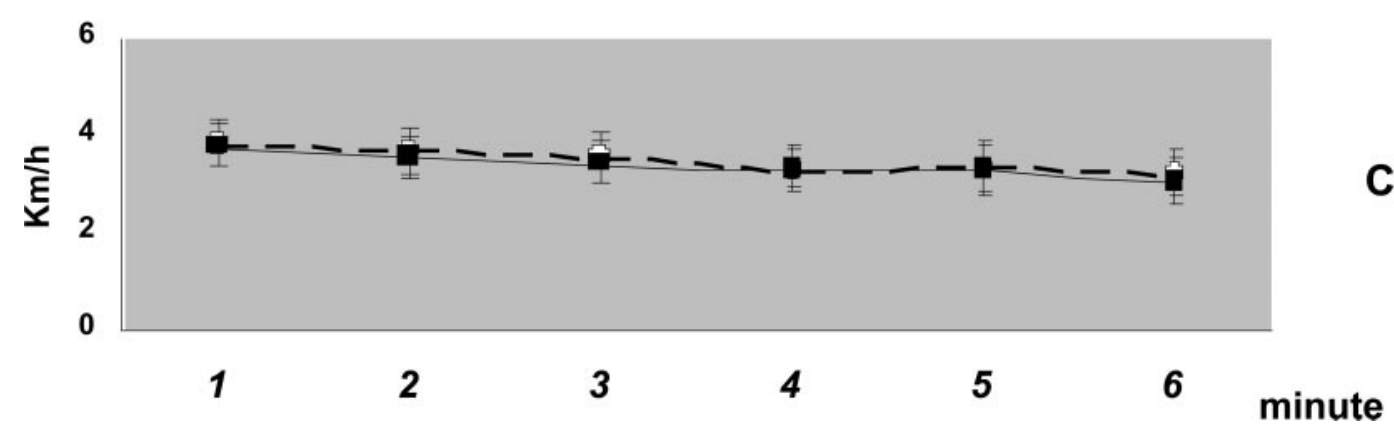

FIGURE 2. Walking speed in kilometers per hour (Km/h) during the 6MWT with No-Aid (solid squares) and Aid (open circles) modalities in the total sample (top, A) and in patients who performed $\leq 300 \mathrm{~m}$ (center, B) or $>300 \mathrm{~m}($ right,$C)$. *p $<0.05$.

ciency who need external oxygen could also benefit from a specific device to help them to carry the oxygen canister during a physical test. Although wheeled walkers offer important advantages over standard walkers (those without wheels), the effect of wheeled walkers or of different tool aids on functional capacity and activities of daily living has not been studied extensively. To our knowledge, this study is the first to explore the effects of a different type of walking aid (wheeled cart) on physical performance.

Basically, our results show that during the timed walking test, the use of a wheeled cart to carry the oxygen canister enabled LTOT users to significantly increase by a mean of approximately $30 \mathrm{~m}$ the distance walked with less dyspnea and leg fatigue, which is a practical objective to be reached in the everyday life of these individuals. Although the minimal change of $+54 \mathrm{~m}$ in 6MWT has been so far suggested as the threshold for a clinically significant improvement after a clinically based intervention, it should be noted that that change was based on a different COPD population with an average baseline distance walked of $>350 \mathrm{~m} \cdot{ }^{19}$ Furthermore, this objective is likely to be reached after a specific and structured therapeutic intervention involving muscular activities like comprehensive pulmonary rehabilitation. $^{2}$ Given that our patients walked approximately $260 \mathrm{~m}$ in the No-Aid modality, the change of $+29 \mathrm{~m}$ with the Aid modality is likely to be meaningful, especially since all had considerable clinical improvements in dyspnea and leg muscle fatigue when walking with the small wheeled cart. As a matter of fact, the mean distance change as obtained in our patients was simply achieved by helping them to move better and to walk with less fatigue.

When looking at the subgroup of subjects with greater disability $(6 \mathrm{MWT}$ distance $<300 \mathrm{~m})$, the change in the distance walked was even more striking (mean gain, $43 \mathrm{~m}$ ), while symptoms were almost reduced to the same extent as in the total sample and in the other subgroup of patients. This fact under- 
lines the significant clinical advantage that even the more disabled and home-bound patients may reach by using this walking strategy.

Analysis of walking speed per minute also confirmed the Aid modality to be a more advantageous way to conduct the timed walking test. Indeed, speed was significantly higher each minute than in the No-Aid modality in subjects with greater disability (Fig 2).

The clinical advantages obtained in our study are likely to be ascribed to the abolished weight and mechanical load on the patient's shoulder girdle during the Aid-modality as compared with the usual No-Aid condition. Solway and coworkers, ${ }^{6}$ in their study on the efficacy of the rollator, have supposed that the benefits reached were not dependent on the amount of total weight (including the rollator) applied to patients but rather on the firm stabilization of their arms on the walker, thus allowing the individual's shoulder girdle muscles to act more effectively as accessory muscle of respiration. ${ }^{19-23}$ However, in this study the electromyographic activity of accessory muscles was not evaluated. The reduction in dyspnea, as well as improvement in exercise capacity, has been observed in previous $\operatorname{articles}^{3,4,7,17}$ in which the effects of a wheeled walking aid were evaluated.

Overall, walking aids allow the patient to stabilize his/her arms, enabling arm and shoulder girdle muscles to participate more effectively as accessory muscles of inspiration, and (eventually) to adopt a forward-leaning position during walking, which is thought to improve the mechanical efficiency of the diaphragm. These mechanisms are two of several mechanisms that could play a role in the reduction of the sensation of dyspnea. Pulling a light cart to carry the oxygen canister also favors stabilization of the arms during walking. Another factor that might have contributed to the reduction of dyspnea and increased walking distance is the sense of confidence and security and equilibrium that the aid offers.

Another, similar study ${ }^{17}$ in which patients wore a portable metabolic system was conducted by the same group of investigators, who confirmed that aiding walking may result in a more efficient performance by incrementing the individual's ventilatory capacity and by reducing the oxygen uptake. ${ }^{17}$ However, the population in that study was less disabled (mean, $416 \mathrm{~m}$ on 6MWT) than the population studied in our trial. Although we cannot extrapolate those conclusions to our study population due to different patient characteristics and to the use of a different walking aid, we are confident that these conclusions may be applied to patients with more severe disease.

Despite the favorable results, our study presents some limitations that need to be addressed. First, our population was selected because of their ability to perform $6 \mathrm{MWT}$, and this was a prerequisite for participation in the study. Nonetheless, it is likely that more disabled patients who are unable to perform a standard time test may benefit from this aid in their everyday activities involving the lower limbs. Second, since this was not a physiologic study, it is possible only to speculate that the overall improvement of the cardiopulmonary response during the Aid modality reflects a true pathophysiologic adaptation of the patients to a different stimulus involving less oxygen uptake and a reduced metabolic response at the skeletal muscle level. It is noteworthy, however, that walking speed was steadily maintained higher during the Aid modality. Thirdly, the favorable result that we obtained in COPD patients, and in the subgroup of more disabled patients in particular, cannot be automatically translated to LTOT users with a different underlying diagnosis (ie, patients with restrictive thoracic diseases).

In conclusion, our study suggests that the use of a wheeled canister may be helpful in COPD patients needing external oxygen, particularly in those with a lower residual exercise capacity. The increase in walking speed, and the reduction in symptoms and oxygen desaturation recorded with aid may translate into a potential physiologic improvement during exercise involving the lower limbs in the patient's everyday life.

ACKNOWLEDGMENT: The authors gratefully thank Ms. Shirley Ann Woods for editorial assistance.

\section{REFERENCES}

1 Canadian Respiratory Review Panel. Guidelines for the treatment of chronic obstructive pulmonary disease (COPD), 1st ed. Toronto, Canada: Medication Use Management Services, 1998

2 Troosters T, Casaburi R, Gosselink R, et al. Pulmonary rehabilitation in chronic obstructive pulmonary disease. Am J Respir Crit Care Med 2005; 172:19-38

3 Honeyman P, Barr P, Stubbing DG. Effect of a walking aid on disability, oxygenation, and breathlessness in patients with chronic airflow limitation. J Cardiopulm Rehabil 1996; 16: 63-67

4 Wesmiller SW, Hoffman LA. Evaluation of an assistive device for ambulation in oxygen dependent patients with COPD. J Cardiopulm Rehabil 1994; 14:122-126

5 Roomi J, Yohannes AM, Connolly MJ. The effect of walking aids on exercise capacity and oxygenation in elderly patients with chronic obstructive pulmonary disease. Age Ageing 1998; 27:703-706

6 Solway S, Brooks D, Lau L, et al. The short-term effect of a rollator on functional exercise capacity among individuals with severe COPD. Chest 2002; 122:56-65

7 Global Initiative for Chronic Obstructive Lung Disease (GOLD). Global Strategy for the diagnosis, management and prevention of Chronic Obstructive Pulmonary Disease: NHLBI/WHO workshop report. Bethesda, MD; National 
Institutes of Health, 2001 (updated 2003); NIH publication 2701. Available at: http://www.goldcopd.com/. Accessed December 19, 2006

8 American Thoracic Society statement: guidelines for the six-minute walk test. Am J Respir Crit Care Med 2002; 166:111-117

9 Quanjer PH, Tammeling GJ, Cotes JE, et al. Lung volumes and forced ventilatory flows: report Working Party Standardization of Lung Function Tests, European Community for Steel and Coal; official statement of the European Respiratory Society. Eur Respir J Suppl 1993; 16:5-40

10 Solway S, Brooks D, Lacasse Y, et al. A qualitative systematic overview of the measurement properties of functional walk tests used in the cardiorespiratory domain. Chest 2001; 119:256-270

11 Borg G. Psychophysical basis of perceived exertion. Med Sci Sports Exerc 1992; 14:377-381

12 Goldstein RS, Gort EH, Stubbing D, et al. Randomized controlled trial of respiratory rehabilitation. Lancet 1994; 344:1394-1397

13 Vergeret J, Brambilla C, Mounier L. Portable oxygen therapy: use and benefit in hypoxaemic COPD patients on long-term oxygen therapy. Eur Respir J 1989; 2:20-25

14 Zielinski J. Current status of home oxygen therapy in various countries: criteria and indications for home oxygen therapy. In: Kira S, Petty TL, eds. Progress in domiciliary respiratory care: current status and perspective. Amsterdam, the Netherlands: Elsevier Science BV, 1994; 3-98

15 Langlois JA, Keyl PM, Guralnik JM, et al. Characteristics of older pedestrians who have difficulty crossing the street. Am J Public Health 1997; 87:393-397

16 Gupta BR, Brooks D, Lacasse Y, et al. Effect of rollator use on health-related quality of life in individuals with COPD. Chest 2006; 130:1089-1095

17 Probst V, Troosters T, Coosemans I, et al. Mechanisms of improvement in exercise capacity using a rollator in patients with COPD. Chest 2004; 126:1102-1107

18 Dalton G, Ashley J, Rudkin ST, et al. The effect of walking aids on walking distance, breathlessness and oxygenation in patients with severe chronic obstructive pulmonary disease (COPD) [abstract]. Thorax 1995; 50(suppl):26

19 Redelmeier DA, Bayoumi AM, Goldstein RS, et al. Interpreting small differences in functional status: the six minute walk test in chronic lung disease patients. Am J Respir Crit Care Med 1997; 155:1278-1282

20 Banzett RB, Topulos GP, Leith DE, et al. Bracing arms increases capacity for sustained hyperpnea. Am Rev Respir Dis 1988; 138:106-109

21 Celli BR. The clinical use of upper extremity exercise. Clin Chest Med 1994; 15:339-349

22 Breslin EH, Garoutte BC, Kohlman-Carrieri V, et al. Correlations between dyspnea, diaphragm, and sternomastoid recruitment during inspiratory resistance breathing in normal subjects. Chest 1990; 98:298-302

23 Eggermont LH, Van Heuvelen MJ, Van Keeken BL, et al. Walking with a rollator and the level of physical intensity in adults 75 years of age or older. Arch Phys Med Rehabil 2006; 87:733-736 
Effects of a Walking Aid in COPD Patients Receiving Oxygen Therapy Ernesto Crisafulli, Stefania Costi, Francesco De Blasio, Gianluca Biscione, Francesca Americi, Sergio Penza, Erika Eutropio, Franco Pasqua, Leonardo M. Fabbri and Enrico M. Clini Chest 2007;131;1068-1074

DOI 10.1378/chest.06-2108

This information is current as of April 10, 2007

\begin{tabular}{|ll|}
\hline $\begin{array}{l}\text { Updated Information } \\
\text { \& Services }\end{array}$ & $\begin{array}{l}\text { Updated information and services, including } \\
\text { high-resolution figures, can be found at: } \\
\text { http://chestjournals.org/cgi/content/full/131/4/1068 }\end{array}$ \\
References & $\begin{array}{l}\text { This article cites } 20 \text { articles, } 6 \text { of which you can access } \\
\text { for free at: } \\
\text { http://chestjournals.org/cgi/content/full/131/4/1068\#BIBL }\end{array}$ \\
Permissions \& Licensing & $\begin{array}{l}\text { Information about reproducing this article in parts } \\
\text { (figures, tables) or in its entirety can be found online at: } \\
\text { http://chestjournals.org/misc/reprints.shtml }\end{array}$ \\
Information about ordering reprints can be found online: \\
http://chestjournals.org/misc/reprints.shtml \\
Remail alerting service & $\begin{array}{l}\text { Receive free email alerts when new articles cite this } \\
\text { article sign up in the box at the top right corner of the } \\
\text { online article. }\end{array}$ \\
Images in PowerPoint format & $\begin{array}{l}\text { Figures that appear in CHEST articles can be } \\
\text { downloaded for teaching purposes in PowerPoint slide } \\
\text { format. See any online article figure for directions. }\end{array}$ \\
&
\end{tabular}

A M E R I C A N C O L L E G E O F C I E S T $\begin{array}{llllllllll}\mathrm{P} & \mathrm{H} & \mathrm{Y} & \mathrm{S} & \mathrm{I} & \mathrm{C} & \mathrm{I} & \mathrm{A} & \mathrm{N} & \mathrm{S}\end{array}$ 